\title{
Influence of Extreme Storage Conditions on Extra Virgin Olive Oil Parameters: Traceability Study
}

\author{
Alfredo Escudero, ${ }^{1}$ Natividad Ramos, ${ }^{1}$ M. Dolores La Rubia, ${ }^{2}$ and Rafael Pacheco ${ }^{2}$ \\ ${ }^{1}$ Physical and Analytical Chemistry Department, University of Jaén, Campus Las Lagunillas s/n, 23071 Jaén, Spain \\ ${ }^{2}$ Chemical, Environmental and Materials Engineering Department, University of Jaén, Campus Las Lagunillas s/n, 23071 Jaén, Spain
}

Correspondence should be addressed to Natividad Ramos; nramos@ujaen.es

Received 20 July 2016; Revised 7 October 2016; Accepted 2 November 2016

Academic Editor: Vito Verardo

Copyright (C) 2016 Alfredo Escudero et al. This is an open access article distributed under the Creative Commons Attribution License, which permits unrestricted use, distribution, and reproduction in any medium, provided the original work is properly cited.

\begin{abstract}
This study reflects the effect of extreme storage conditions on several extra virgin olive oil (EVOO) varieties (arbequina, hojiblanca, and picual). The conditions were simulated in the laboratory, by means of heating treatments in stove at different temperatures (40 and $60^{\circ} \mathrm{C}$ ) and times (two and three weeks). The aim is the evaluation of the deterioration of the quality parameters and minority components, which are responsible for the nutritional and therapeutic properties (fatty acids, polyphenols, pigments, and tocopherols), and organoleptic qualities. The quality criteria and limits used in this work are according to International Olive Council. The results contribute to the control of the traSceability for the commercialization of the EVOO.
\end{abstract}

\section{Introduction}

Actually, consumers and public authorities consider food safety and quality a fundamental priority because they are closely connected with the health of consumers.

Therefore, to guarantee the food safety, the policies must be based on a global and integrated approach of every link in the food chain (traceability), since all of them affect the innocuousness and the quality of the food. Likewise, the conservation and manipulation by the consumer are intimately related to the food safety, for which it is a fundamental aspect to know in which conditions the food will be altered as a consequence of the influence of different physical or chemical factors or environmental conditions.

The Regulation (EC) number 852/2004 of the European Parliament and of the Council of 29 April 2004 on the hygiene of foodstuffs [1] states the need of working under a selfchecking system to ensure food safety throughout the food chain. The olive oil elaboration presents multiple risk steps that can concern its qualities and the food safety. The identification of any hazards and the application of preventive measures are crucial to obtain a safe final product with high quality. At the same time it is necessary to consider the
Spanish Law 12/2013 of 2 August which gives measures to improve the functioning of the food chain [2].

The virgin olive oil is the only cooking oil that is made without the use of chemicals and industrial refining and its consumption in countries outside Mediterranean area is quickly rising. The main reasons are its sensory, antioxidant, and therapeutics properties derived from components and especially from the minor ones, as polyphenols and tocopherols, with antioxidant properties, which prevent cancer and degenerative diseases [3-6]. The health benefits of olive oil are unrivaled, and research reveals more benefits nearly every day. However, over time, oil deteriorates and its properties are altered or modified, in particular if they are used under thermal conditions which affect its stability and quality.

Every stage of the olive oil elaboration affects the organoleptic characteristics (flavor, smell, etc.) and the quality of the oil, specially of the virgin olive oil (VOO) and extra virgin olive oil (EVOO), growth, plant health, phytosanitary treatments, harvest and transport, storage, or paste preparation. During the storage and transport the VOOs and EVOOs are affected by unstable temperatures over time which alter the oil quality as a consequence of the degradation of some components. 
Different papers considered the evolution of the quality parameters and the VOOs self-life during storage periods between 12 and 24 months in oil mill storage tanks [7], in bottles [8-11], in tin containers [12], in commercial conditions [13], and in home conditions [14]. The results of these studies have contributed to a better understanding of the chemical oxidation process, but they were inconclusive.

In the last decade the VOO quality prediction and the evolution of the antioxidant components during storage are themes of great interest. Several authors have analyzed the alteration of the fatty acid composition, minor components, and antioxidant activity during storage [5, 15-17]. The latter authors reported the evolution of major and minor components and oxidation indices of seven VOO samples, which differed in their initial contents of natural antioxidants significantly, during 21 months of storage at room and in darkness. The correlation between the initial composition and time to reach the upper limits established by EU Regulation is also reported.

Morelló et al. [18] observed a great decrease in the minor components in particular for the phenolic fraction and pigments while the oleic acid percentage increases in commercial arbequina VOO after 12 months at room temperature. Also, the influence of the VOO elaboration methods on the quality parameters during 18 months of storage has been studied [19]. Other research studies evaluate the oxidative capacity of the VOO under high temperature accelerated storage conditions (50 $\mathrm{C}$ during 8 months) [20].

In recent years, several authors [21-23] have reported results of different olive oil varieties under storage conditions between $+4^{\circ} \mathrm{C}$ and $-20^{\circ} \mathrm{C}$ during 12 months. The quality of the VOO remains better at low temperatures, the phenolic content decreased slightly, and the volatile compounds were unaltered. Low temperatures preserve the organoleptic properties of a fresh oil better than room temperatures.

Mulinacci et al. [24] compared the effect of a long storage period on $\mathrm{EVOO}$ at $-23^{\circ} \mathrm{C}$ with the same specimens at room temperature in dark. The evolution of the phenolic composition and aromatic profile were monitored during 18 months. Increments of the phenolic composition were observed for oils stored at room temperature starting from 3 months of storage, and the frozen oils showed negligible differences in aromatic profile until 12 months of storage.

The influence of storage conditions and packing materials (clear PET, can, glass, and tetrabrick) on olive oil quality has been considered in different papers [25-30].

The tetrabrick packing preserves the original olive oil quality better than PET and glass which were responsible for a decrease of the quality parameters and minor components (pigments and tocopherols). This reveals the influence of the packing materials on the protection and quality of the olive oil.

Finally, the influence of the temperature on the vegetable oils during thermal treatment (simulating cooking) and its influence on the physical-chemical parameters have been also studied [31-33]. The studied oils were VOO, EVOO, sunflower oil (refined and high oleic content), peanut oil, and cottonseed oil and a microwave oven was used as energy source. A conventional oven was also used by some authors in order to compare results [34-37].

Therefore, as there has been little knowledge about the influence of high temperatures on the quality parameters and minor components of the EVOOs, in this research the long term storage at high temperatures is simulated. The objective of this study is to simulate inappropriate transport and storage conditions which affect the EVOO quality and could alter its "extra" denomination and evaluate the physical-chemical and sensorial properties of the EVOO under these conditions.

For these purposes, four extra virgin olive oils (picual (two brands), arbequina, and hojiblanca) from Jaén (Spain) were investigated. The accelerated assays were carried out in a laboratory oven at high temperatures and time simulating several transport or storage conditions in Andalusia region or areas with similar climatology where the temperatures in summer seasons are high.

In addition, the interest of this paper lies in the fact that the VOO export is increasing strongly and the influence of the long term transport and storage conditions has not been studied. The results will improve international transport conditions in terms of length, in order to guarantee the original characteristics in destination and to comply with the Food Safety Regulations.

\section{Materials and Methods}

2.1. Preparation of the Samples. Commercial samples of EVOO of the varieties: picual (two brands A and B), arbequina, and hojiblanca of the crop, in season 2012-2013 were collected from Andalusia. All the samples, bottled in clear PET, were purchased from local stores and oil mills. The olive oil samples were stored correctly up to the beginning of the experimental procedure.

Four studies were carried out: storage in a Mecánicas Científicas S.A. oven with air flow from the external environment at $40^{\circ} \mathrm{C}$ during two and three weeks (treatment $\mathrm{T} 1$ and treatment $\mathrm{T} 2$ ) and $60^{\circ} \mathrm{C}$ during two and three weeks (treatment T3 and treatment T4). After each treatment the samples were coded, placed in amber glass, and frozen until analysis. All the measurements were made in triplicate.

2.2. Quality Parameters. The quality parameters were determined according to the analytical methods described in the COI/T.15/NC number 3/Rev. 7 May of 2013 and (UE) 2015/ 1830 Regulation of the Commission 8 of July of $2015[38,39]$.

The content of free fatty acids is expressed as acidity calculated conventionally. For this determination $20 \mathrm{~g}$ of oil is dissolved in $50 \mathrm{~mL}$ of the previously neutralized mixture of ethanol-ether $(1: 1 \mathrm{v} / \mathrm{v})$. The sample is titrated with potassium hydroxide using phenolphthalein as indicator. The acidity is expressed as percentage of oleic acid.

Peroxide value (PV) was expressed as milliequivalent of active oxygen per kilogram of oil. 1.2-2.0 $\mathrm{g}$ of oil was dissolved in a mixture of chloroform and acetic acid $(2: 3 \mathrm{v} / \mathrm{v})$. Then $1 \mathrm{~mL}$ of KI saturated solution was added and $75 \mathrm{~mL}$ of deionized water was also added after stirring and $5 \mathrm{~min}$ in darkness. Finally the sample is titrated with sodium thiosulphate and starch solution as indicator. 
TABLE 1: Quality parameters.

\begin{tabular}{|c|c|c|c|c|c|}
\hline & Control sample & $\mathrm{T} 1$ & $\mathrm{~T} 2$ & T3 & $\mathrm{T} 4$ \\
\hline \multicolumn{6}{|l|}{ Picual A } \\
\hline Acidity grade & $0.090 \pm 0.001$ & $0.140 \pm 0.001$ & $0.180 \pm 0.002$ & $0.130 \pm 0.001$ & $0.130 \pm 0.001$ \\
\hline$K_{232}$ & $1.77 \pm 0.05$ & $1.66 \pm 0.01$ & $1.74 \pm 0.01$ & $1.84 \pm 0.02$ & $1.71 \pm 0.01$ \\
\hline \multicolumn{6}{|l|}{ Picual B } \\
\hline Acidity grade & $0.110 \pm 0.001$ & $0.140 \pm 0.002$ & $0.110 \pm 0.001$ & $0.110 \pm 0.001$ & $0.110 \pm 0.002$ \\
\hline$K_{232}$ & $1.89 \pm 0.04$ & $1.79 \pm 0.06$ & $1.80 \pm 0.02$ & $1.88 \pm 0.07$ & $1.97 \pm 0.06$ \\
\hline \multicolumn{6}{|l|}{ Arbequina } \\
\hline Acidity grade & $0.060 \pm 0.003$ & $0.080 \pm 0.001$ & $0.090 \pm 0.001$ & $0.080 \pm 0.002$ & $0.090 \pm 0.003$ \\
\hline$K_{232}$ & $0.93 \pm 0.01$ & $0.96 \pm 0.04$ & $0.98 \pm 0.01$ & $0.94 \pm 0.01$ & $2.15 \pm 0.02$ \\
\hline \multicolumn{6}{|l|}{ Hojiblanca } \\
\hline Acidity grade & $0.030 \pm 0.002$ & $0.100 \pm 0.004$ & $0.090 \pm 0.003$ & $0,080 \pm 0.002$ & $0.080 \pm 0.002$ \\
\hline$K_{232}$ & $0.72 \pm 0.03$ & $0.73 \pm 0.02$ & $0.78 \pm 0.02$ & $0.72 \pm 0.03$ & $1.84 \pm 0.05$ \\
\hline
\end{tabular}

Results expressed as mean value \pm typical deviation.

$K_{232}$ and $K_{268}$ extinction coefficients were calculated by spectrophotometric examination in the ultraviolet. $100 \mathrm{mg}$ of oil was dissolved in $25 \mathrm{~mL}$ of isooctane and the extinction of the solution is then determined at the specified wavelengths with reference to pure solvent. Specific extinctions are calculated from the spectrophotometer readings (Varian Cary 4000 ) using a quartz cell with a $1 \mathrm{~cm}$ optical path.

The testing panel of The Technological Center of the Olive Grove and Olive Oil (CITOLIVA) carried out the sensory characterization and linked the flavor stimuli of the EVOOs with a numeric scale according to the analytical methods described in the European Commission Regulation number 2568/91 and subsequent amendments (number 1348/2013) [39].

2.3. Purity Parameters. The gas chromatography (GC) is the analytical technique used to determine the qualitative and quantitative fatty acid methyl-esters composition [39]. The samples were prepared by shaking a solution of oil in heptane $(0.1 \mathrm{~g}$ in $2 \mathrm{~mL})$ with $0.2 \mathrm{~mL}$ of $2 \mathrm{~N}$ methanolic potassium hydroxide stirred during 30 seconds. The methyl-esters were analyzed from the supernatant solution by gases chromatographer Shimadzu GC-2014AF/SP. The oven temperature was set at $185^{\circ} \mathrm{C}$, and the injector and detector temperatures were set at $220^{\circ} \mathrm{C}$. The chromatograms were read in ascending order of number of carbons and unsaturations.

2.4. Minor Components. The tocopherols were evaluated by HPLC following the method described by Cunha et al. [40] on a Shimadzu HPLC mod. Prominence serie 20. A SigmaAldrich $(250 \mathrm{mg} / \mathrm{L}) \alpha$-tocopherol in acetonitrile was frozen at $-20^{\circ} \mathrm{C}$ until being used as internal pattern. $0.2 \mathrm{~g}$ of oil was dissolved in $10 \mathrm{~mL}$ of $\mathrm{n}$-hexane and $20 \mu \mathrm{L}$ of sample was analyzed. As mobile phase hexane was used: isopropanol $(97: 3 \mathrm{v} / \mathrm{v})$ in isocratic conditions and $1 \mathrm{~mL} / \mathrm{min}$ of flow rate. The chromatograms were recorded at $275 \mathrm{~nm}$. The results are expressed as mg of $\alpha$-tocopherol per oil kg.

Chlorophyll and carotenoids compounds were determined at 472 and $670 \mathrm{~nm}$ (maximum absorption wavelength of pheophytin and lutein) in cyclohexane by the method of
Mínguez [41], by a Varian Cary 4000 spectrophotometer. The chlorophyll and carotenoid concentration was expressed as milligrams of pigment per kilogram of oil.

The total polyphenols were determined following the method described by Vázquez-Roncero et al. [42], using the Folin-Ciocalteau reagent. The olive oil sample was dissolved in hexane and the phenolic compounds were extracted by triple extraction by methanol : water $(60: 40 \mathrm{v} / \mathrm{v})$, by decantation. A mixture of $5 \mathrm{~mL}$ of polyphenols extract was mixed in $35 \mathrm{~mL}$ of water and $2.5 \mathrm{~mL}$ of Folin-Ciocalteau reagent. The mixture was homogenized by agitation and finally $5 \mathrm{~mL}$ of $\mathrm{Na}_{2} \mathrm{CO}_{3}$ saturated was added. The absorption of the solution was measured at $725 \mathrm{~nm}$. Results were given as $\mathrm{mg} / \mathrm{kg}$ of caffeic acid.

2.5. Statistical Analysis. The multifactorial analysis of variance (ANOVA) was performed using Statgraphics Centurion software. This analysis is designed to build a statistical model describing the impact of two or more categorical factors of a dependent variable. Tests were done to find out any significant differences between the media values and any interactions between the factors. The ANOVA table shows the decomposition of the variability of the measurable parameter in contributions of different factors. As the sum of the squares (type III) was selected, the interaction of each factor is determined eliminating the other factors' effects. The values of $P$ indicate the statistical significance of each factor.

\section{Results and Discussion}

Three monovarietal extra virgin olive oils have been studied in this research, arbequina, picual (two brands $\mathrm{A}$ and $\mathrm{B}$ ), and hojiblanca, making a total of four EVOOs. This section describes the results obtained and discusses the influence of the experimental conditions on the quality parameter and minor components of the EVOOs.

Tables 1 and 2 show the values of the quality parameters and minor components of each sample of extra virgin olive oil at the beginning of the assay (control sample) and after each treatment ( $\mathrm{T} 1$ to $\mathrm{T} 4$ ). 
TABLE 2: Fatty acid composition.

\begin{tabular}{|c|c|c|c|c|c|}
\hline & Control sample & $\mathrm{T} 1$ & $\mathrm{~T} 2$ & $\mathrm{~T} 3$ & $\mathrm{~T} 4$ \\
\hline \multicolumn{6}{|c|}{ Picual A } \\
\hline $\mathrm{C} 16: 0$ & $10.52 \pm 0.12$ & $10.41 \pm 0.04$ & $10.38 \pm 0.05$ & $10.36 \pm 0.35$ & $10.43 \pm 0.41$ \\
\hline $\mathrm{C} 16: 1$ & $0.81 \pm 0.01$ & $0.81 \pm 0.01$ & $0.82 \pm 0.01$ & $0.81 \pm 0.03$ & $0.80 \pm 0.01$ \\
\hline $\mathrm{C} 17: 0$ & $0.050 \pm 0.007$ & $0.050 \pm 0.003$ & $0.050 \pm 0.004$ & $0.050 \pm 0.006$ & $0.050 \pm 0.006$ \\
\hline $\mathrm{C} 17: 1$ & $0.090 \pm 0.001$ & $0.090 \pm 0.003$ & $0.100 \pm 0.001$ & $0.100 \pm 0.001$ & $0.090 \pm 0.001$ \\
\hline C18:0 & $3.40 \pm 0.03$ & $3.30 \pm 0.05$ & $3.24 \pm 0.02$ & $3.23 \pm 0.04$ & $3.33 \pm 0.02$ \\
\hline C18:1 & $80.47 \pm 0.45$ & $80.01 \pm 0.08$ & $80.05 \pm 0.09$ & $80.20 \pm 0.17$ & $79.98 \pm 0.08$ \\
\hline C18:2 & $4.06 \pm 0.03$ & $4.08 \pm 0.03$ & $4.04 \pm 0.01$ & $4.04 \pm 0.03$ & $4.02 \pm 0.01$ \\
\hline C20:0 & $0.620 \pm 0.023$ & $0.640 \pm 0.003$ & $0.660 \pm 0.002$ & $0.650 \pm 0.005$ & $0.640 \pm 0.001$ \\
\hline C20:1 & $0.41 \pm 0.01$ & $0.41 \pm 0.01$ & $0.42 \pm 0.05$ & $0.40 \pm 0.01$ & $0.40 \pm 0.04$ \\
\hline $\mathrm{C} 18: 3$ & $0.23 \pm 0.03$ & $0.24 \pm 0.01$ & $0.28 \pm 0.04$ & $0.26 \pm 0.01$ & $0.27 \pm 0.03$ \\
\hline \multicolumn{6}{|c|}{ Picual B } \\
\hline $\mathrm{C} 16: 0$ & $10.92 \pm 0.05$ & $10.73 \pm 0.09$ & $10.41 \pm 0.22$ & $10.60 \pm 0.16$ & $6.01 \pm 0.02$ \\
\hline C16:1 & $0.90 \pm 0.01$ & $0.89 \pm 0.07$ & $0.91 \pm 0.02$ & $0.90 \pm 0.02$ & $0.47 \pm 0.42$ \\
\hline $\mathrm{C} 17: 0$ & $0.060 \pm 0.005$ & $0.040 \pm 0.003$ & $0.040 \pm 0.001$ & $0.050 \pm 0.001$ & $0.040 \pm 0.007$ \\
\hline $\mathrm{C} 17: 1$ & $0.090 \pm 0.003$ & $0.130 \pm 0.039$ & $0.090 \pm 0.004$ & $0.080 \pm 0.001$ & $0.090 \pm 0.004$ \\
\hline C18:0 & $3.11 \pm 0.02$ & $3.08 \pm 0.04$ & $2.90 \pm 0.04$ & $3.03 \pm 0.06$ & $3.33 \pm 0.21$ \\
\hline C18:1 & $80.14 \pm 0.080$ & $80.39 \pm 0.082$ & $80.89 \pm 0.232$ & $80.57 \pm 0.230$ & $85.09 \pm 4.956$ \\
\hline C18:2 & $3.44 \pm 0.09$ & $3.43 \pm 0.02$ & $3.47 \pm 0.03$ & $3.44 \pm 0.06$ & $3.60 \pm 0.20$ \\
\hline C20:0 & $0.660 \pm 0.007$ & $0.660 \pm 0.003$ & $0.670 \pm 0.011$ & $0.670 \pm 0.003$ & $0.70 \pm 0.041$ \\
\hline C20:1 & $0.410 \pm 0.001$ & $0.400 \pm 0.002$ & $0.380 \pm 0.004$ & $0.410 \pm 0.008$ & $0.420 \pm 0.028$ \\
\hline $\mathrm{C} 18: 3$ & $0.280 \pm 0.018$ & $0.260 \pm 0.005$ & $0.250 \pm 0.001$ & $0.270 \pm 0.001$ & $0.270 \pm 0.015$ \\
\hline \multicolumn{6}{|c|}{ Arbequina } \\
\hline $\mathrm{C} 16: 0$ & $11.45 \pm 0.02$ & $11.06 \pm 0.24$ & $10.80 \pm 0.51$ & $11.31 \pm 0.05$ & $12.06 \pm 0.07$ \\
\hline C16:1 & $1.38 \pm 0.07$ & $1.44 \pm 0.07$ & $1.42 \pm 0.02$ & $1.43 \pm 0.07$ & $1.40 \pm 0.01$ \\
\hline $\mathrm{C} 17: 0$ & $0.130 \pm 0.010$ & $0.120 \pm 0.003$ & $0.130 \pm 0.001$ & $0.120 \pm 0.009$ & $0.130 \pm 0.001$ \\
\hline $\mathrm{C} 17: 1$ & $0.280 \pm 0.009$ & $0.260 \pm 0.008$ & $0.270 \pm 0.001$ & $0.270 \pm 0.001$ & $0.270 \pm 0.002$ \\
\hline C18:0 & $1.95 \pm 0.04$ & $2.03 \pm 0.06$ & $2.03 \pm 0.01$ & $2.06 \pm 0.07$ & $2.07 \pm 0.04$ \\
\hline C18:1 & $74.13 \pm 0.02$ & $74.43 \pm 0.17$ & $74.64 \pm 0.34$ & $74.18 \pm 0.04$ & $73.62 \pm 0.06$ \\
\hline C18:2 & $9.02 \pm 0.07$ & $9.10 \pm 0.04$ & $9.12 \pm 0.10$ & $9.00 \pm 0.04$ & $8.88 \pm 0.07$ \\
\hline C20:0 & $0.690 \pm 0.014$ & $0.650 \pm 0.005$ & $0.640 \pm 0.002$ & $0.670 \pm 0.032$ & $0.630 \pm 0.002$ \\
\hline C20:1 & $0.410 \pm 0.015$ & $0.410 \pm 0.002$ & $0.430 \pm 0.020$ & $0.440 \pm 0.018$ & $0.420 \pm 0.001$ \\
\hline C18:3 & $0.350 \pm 0.020$ & $0.370 \pm 0.020$ & $0.370 \pm 0.010$ & $0.360 \pm 0.016$ & $0.360 \pm 0.002$ \\
\hline \multicolumn{6}{|c|}{ Hojiblanca } \\
\hline $\mathrm{C} 16: 0$ & $9.93 \pm 0.02$ & $8.72 \pm 0.01$ & $10.12 \pm 0.06$ & $10.47 \pm 0.08$ & $10.44 \pm 0.04$ \\
\hline C16:1 & $0.820 \pm 0.001$ & $0.850 \pm 0.008$ & $0.850 \pm 0.007$ & $0.820 \pm 0.006$ & $0.820 \pm 0.006$ \\
\hline $\mathrm{C} 17: 0$ & $0.100 \pm 0.002$ & $0.100 \pm 0.001$ & $0.100 \pm 0.002$ & $0.110 \pm 0.002$ & $0.450 \pm 0.002$ \\
\hline $\mathrm{C} 17: 1$ & $0.570 \pm 0.003$ & $0.180 \pm 0.003$ & $0.170 \pm 0.001$ & $0.170 \pm 0.001$ & $0.240 \pm 0.004$ \\
\hline C18:0 & $3.18 \pm 0.05$ & $3.03 \pm 0.01$ & $3.08 \pm 0.02$ & $3.32 \pm 0.01$ & $3.31 \pm 0.02$ \\
\hline C18:1 & $77.25 \pm 0.07$ & $78.82 \pm 0.06$ & $77.63 \pm 0.03$ & $77.14 \pm 0.07$ & $76.82 \pm 0.32$ \\
\hline C18:2 & $6.58 \pm 0.04$ & $6.78 \pm 0.01$ & $6.56 \pm 0.05$ & $6.48 \pm 0.02$ & $6.45 \pm 0.02$ \\
\hline C20:0 & $0.760 \pm 0.005$ & $0.780 \pm 0.003$ & $0.760 \pm 0.001$ & $0.750 \pm 0.003$ & $0.730 \pm 0.001$ \\
\hline C20:1 & $0.430 \pm 0.003$ & $0.420 \pm 0.004$ & $0.420 \pm 0.001$ & $0.440 \pm 0.001$ & $0.430 \pm 0.006$ \\
\hline $\mathrm{C} 18: 3$ & $0.300 \pm 0.003$ & $0.310 \pm 0.008$ & $0.300 \pm 0.007$ & $0.300 \pm 0.000$ & $0.310 \pm 0.008$ \\
\hline
\end{tabular}

3.1. Acidity. The acidity of the arbequina and hojiblanca EVOO control samples was lower than the fixed limit by the European and International Regulations, while, for both picual brands (A and B), the acidity values were slightly higher, 0.09 and 0.11 , respectively.
As can be seen, the initial acidity grade of the arbequina and hojiblanca olive oils was unaltered after the heating treatment, and their values ranged from 0.08 to 0.09 . According to this parameter these samples preserve the extra virgin olive oil category. However, the samples of picual variety changed 


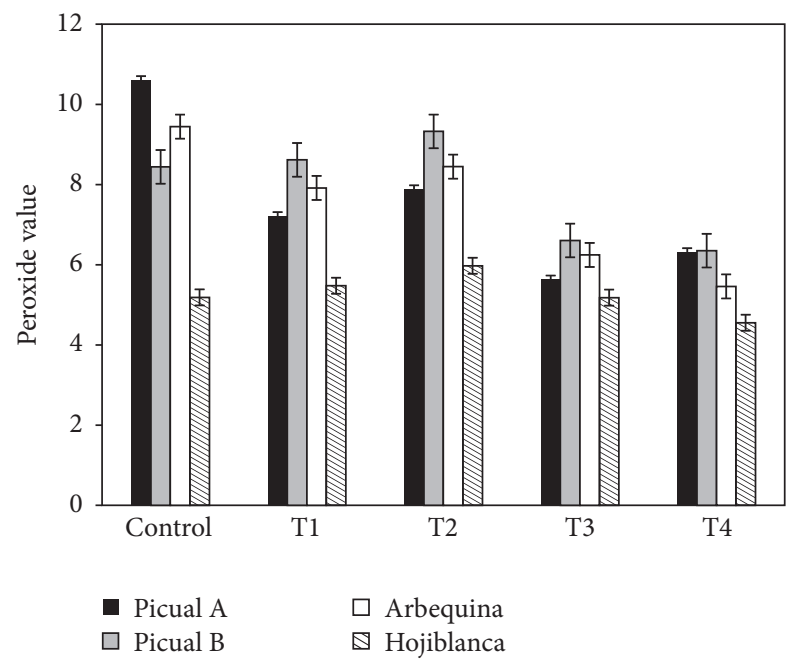

FIGURE 1: Influence of the heating treatments on the peroxide value of the olive oils.

their designation to "virgin" due to an increase of the AG of 0.13 and 0.14 , respectively.

This trend has been also noted by other authors who studied the olive oil stability after heating with different exposure times in microwave and conventional oven [34, 4346].

The results indicate that the treatment at $40^{\circ} \mathrm{C}$ produces the largest increase of the acidity with increases of $86 \%$, while treatment at $60^{\circ} \mathrm{C}$ during two and three weeks causes an increase of $67 \%$ and $64 \%$, respectively. The acidity of the arbequina variety olive oil is the least affected with the treatment, two of the samples are unaffected, and the rest shows an acidity increase of $15 \%$ in comparison to $54 \%$ of the picual variety brand $\mathrm{B}, 37 \%$ of picual variety brand $\mathrm{A}$, and $204 \%$ of hojiblanca variety.

3.2. Peroxide Value $(P V)$. According to the current legislation, at the beginning of the storage the oil samples had low levels of PV and fall into the extra virgin olive oil category. These initial peroxide values were 10.60 picual A, 8.44 picual B, 5.19 hojiblanca, and 9.44 arbequina (Table 1).

A significant decrease in PV occurred in the picual and arbequina samples after the treatment with a decrease of 20$30 \%$. However no significant changes were observed for the hojiblanca variety samples. These results confirm that all the olive oil varieties studied preserve their extra virgin olive oil category after the time-temperature treatments.

Figure 1 shows that the treatment at $60^{\circ} \mathrm{C}$ causes the greatest impact in the PV decreasing the PV levels in all the olive oil samples studied.

Comparing the results with other authors who use different energy sources [37], no significant changes in PV with time are observed in microwave heating while PV decreases are detected after heating in conventional oven or frying (about 50\%).

However, there is no consensus in literature about the PV evolution of olive oils after heating treatments. Albi et al. [34] reported a slight increase of the PV of the extra virgin olive

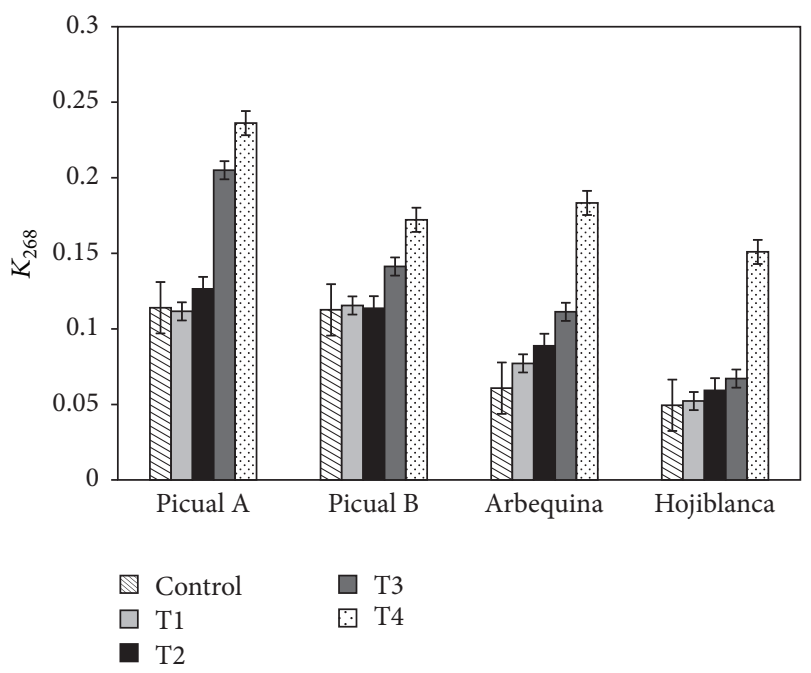

FIgURE 2: Variation of $K_{268}$ with the treatments.

oil after $120 \mathrm{~min}$ of microwave heating at $170^{\circ} \mathrm{C}$ while this parameter decreases in a virgin olive oil after being exposed to the same conditions. Cossignani et al. [31] also noted an increase of the PV of the extra virgin olive oil after a microwave heating of 8 minutes.

The behavior of the PV could be explained by the evolution of the oxidation process, the PV increase is caused by the hydroperoxide formation, and the appearance of secondary oxidation products reduces the PV.

3.3. $K_{232}$ and $K_{268}$ Extinction Coefficients. The UV spectrophotometric study provides information about the degree of olive oil oxidation and therefore its quality [38]. The $K_{232}$ extinction coefficients indicate the conjugation of dienes formation of the polyunsaturated fatty acids (primary oxidation), while the $K_{268}$ extinction coefficients are indicators of the presence of secondary oxidation products, including conjugated trienes and carbonyl compounds.

The maximum values permitted for $K_{232}$ and $K_{268}$ are, respectively, 2.50 and 0.22 for extra virgin olive oils and 2.60 and 0.25 for virgin olive oil, respectively.

Table 1 and Figure 2 show the $K_{232}$ and $K_{268}$ extinction coefficient evolution with the heating treatment.

All the olive oil samples presented $K_{232}$ and $K_{268}$ values lower than the maximum limits established for the extra virgin category (2.50 and 0.22 for $K_{232}$ and $K_{268}$, resp.) at the initial stage and after each time-temperature treatment.

However only one sample of picual variety presents a $K_{268}$ value of 0.24 after three weeks at $60^{\circ} \mathrm{C}$, and this value is the nearest to the maximum limit stablished for EVOO category.

In relation to the effect of the heating treatment the highest increment of the coefficient $K_{232}$ is observed after 3 weeks at $60^{\circ} \mathrm{C}$ for all the samples with the exception of the picual A olive oil whose coefficient reaches the highest increase after 2 weeks at $60^{\circ} \mathrm{C}$. The treatments at $60^{\circ} \mathrm{C}$ have the greatest impact on the $K_{268}$ coefficients (Figure 2).

The effect of the heating on the quality parameters of the olive oil has been also studied by several authors with 

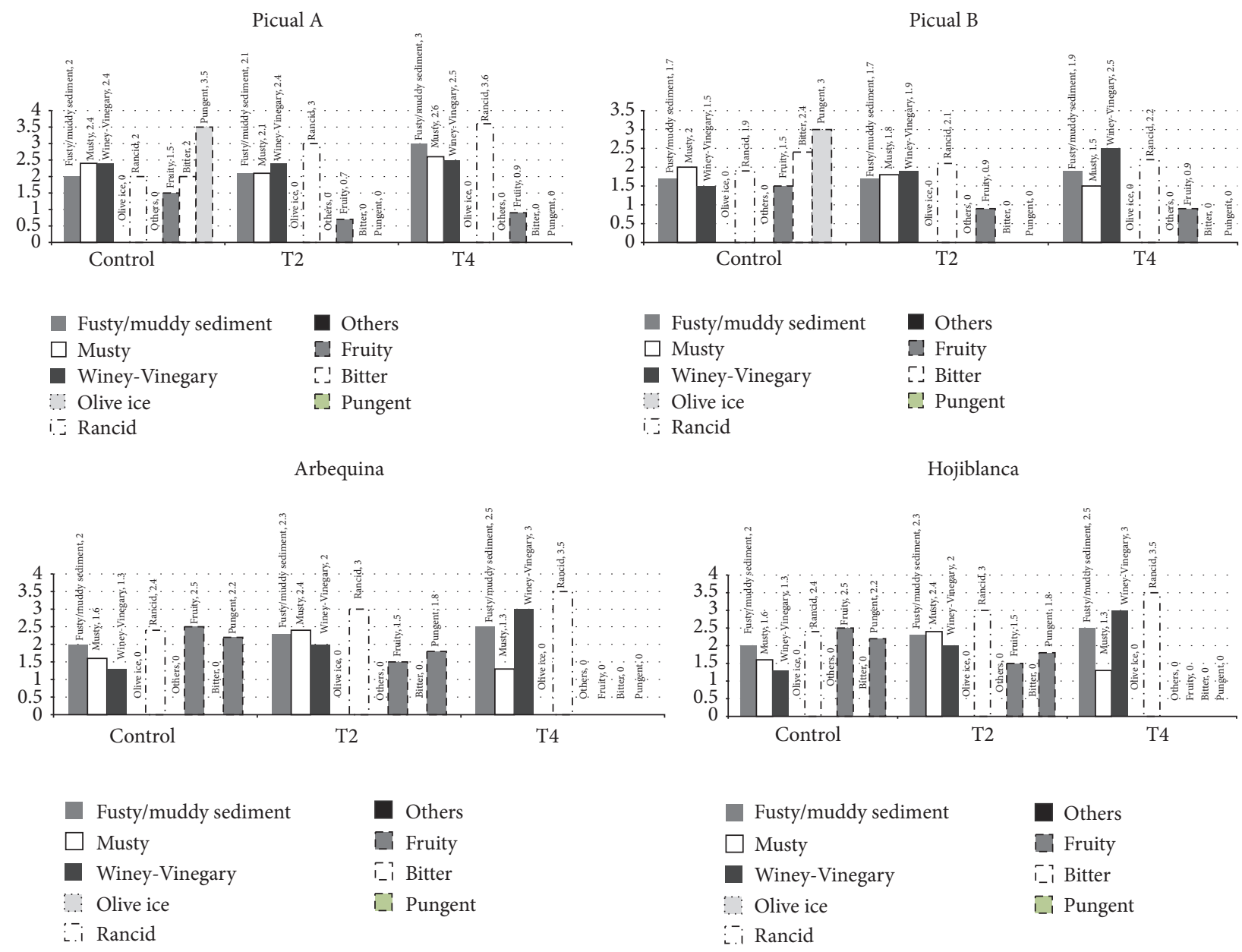

Figure 3: Influence of the heating treatments on the sensory analysis. Positive features and defects.

similar results. Malheiro et al. [32] reported increases of the $K_{232}$ coefficient after microwave heating. In this study all oils presented $K_{232}$ higher than 3.1 after $15 \mathrm{~min}$ of heating that indicates an accelerated degradation process and therefore the olive oils no longer correspond to the extra virgin category.

This behavior is observed in all the olive oil varieties studied. No relevant changes were observed in the olive oils after the treatment in the conventional oven or during frying. However a significant increase of the $K_{268}$ extinction coefficient is observed in all the varieties after each heating treatment in both the conventional oven heating and microwave heating. This increase with the time is due to the formation of oxidation compounds which explained the PV decrease $[32,37,43]$.

3.4. Sensory Evaluation. The sensory evaluation of the olive oils was developed following the Regulation (EEC) number 2568/91 on the characteristics of olive oil and olive-residue oil and on the relevant methods of analysis and the amendment in the Regulation (EEC) number 1348/2013 [39] which graded the olive oils categories in line with the median of the defects and the median for "fruity."
Figure 3 shows the median of the positive features and defects selected for each stove heating treatment. It can be observed that none of the olive oils studied preserves the "extra virgin" category, some of them became virgin category, and the picual and arbequina varieties of olive oils became "lampante" category after three weeks at $60^{\circ} \mathrm{C}$. Figure 4 shows the sensory profiles of all the olive oils studied.

3.5. Fatty Acid Profile. The changes of the fatty acid percentages could be probably due to the chemical reactions (oxidation, hydrolysis) as a consequence of the heating treatments. The thermolability or volatility of these compounds has great influence [44].

As Table 2 shows, the fatty acid composition was unaltered for all the olive oil varieties. These profiles were in all the samples according to the "extra virgin" category in compliance with the requirements of the European Regulations [38] for the EVOO denomination. Only the arachidic acid and gadoleic acid content were initially slightly higher than the EU limits of 0.60 and 0.40 , respectively. The results of this research are similar to other studies [35] where the fatty acid profiles of different vegetable oils after microwave and conventional heating treatments were unchanged. Table 2 

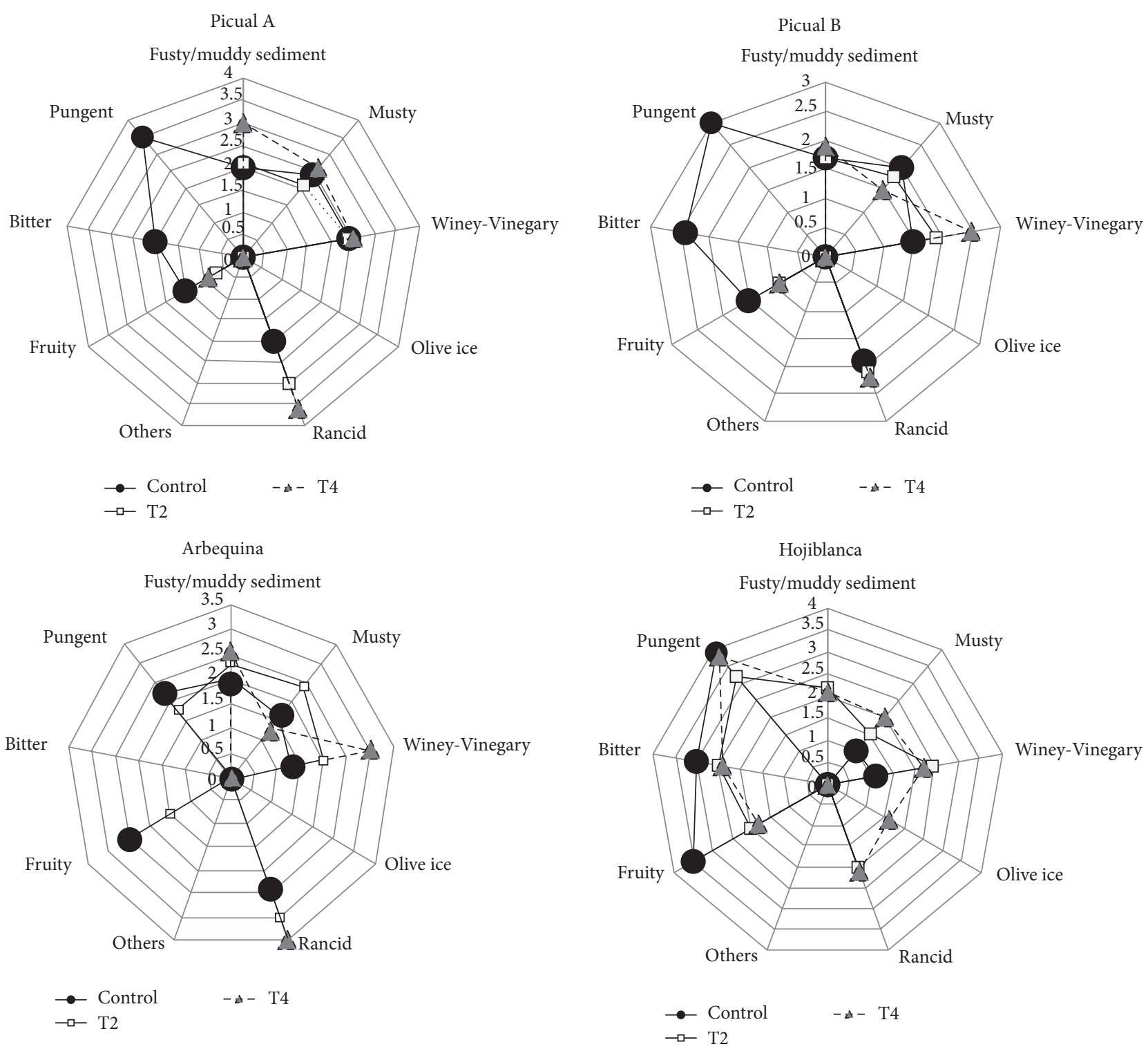

FIGURE 4: Sensory profile of the olive oils after 3 weeks at $40^{\circ} \mathrm{C}(\mathrm{T} 2)$ and 3 weeks at $60^{\circ} \mathrm{C}(\mathrm{T} 4)$.

shows medium values and the variability expressed as typical deviation.

3.6. Minority Compounds: Pigments, Polyphenols, and Tocopherols. Unlike the results obtained by Malheiro et al. [32] and Yahyaoui et al. [45], the heating treatments at $40^{\circ} \mathrm{C}$ and $60^{\circ} \mathrm{C}$ for two and three weeks have no influence on both chlorophyll and carotenoid concentrations (Figures 5(a) and 5(b)). Indeed they can be considered constant values for all the oils, except in the picual sample whose value diminished by $50 \%$ as time and temperature increase.

The polyphenols content expressed as mg of caffeic acid per $\mathrm{kg}$ of oil remains relatively unchanged with the heating treatments in stove. However, other researches [34, 36, 45, 46] have shown that the microwave heating treatments decrease the antioxidant components content between $55 \%$ and $85 \%$.

With regard to the content of tocopherols, expressed as $\mathrm{mg} / \mathrm{kg}$ of $\alpha$-tocopherol, different trends are shown in
Figure 5(d). The tocopherol content is unchanged for the picual B sample. A rise of this content is observed for the arbequina variety oils and picual B and hojiblanca variety oils decrease this content between $47 \%$ and $70 \%$, respectively, as time and temperature increase, with a maximum value after 3 weeks at $60^{\circ} \mathrm{C}$.

3.7. Influence of the Variety, Time, and Temperature. The results of the multifactorial statistical analysis, ANOVA, with the objective of study being the influence of the three variables studied (variety, time, and temperature) on the quality parameters are shown in Table 3 . The $P$ values show that the most significant variable is the variety with $P<0.05$ for all the parameters. Temperature shows $P<0.05$ for $50 \%$ of the parameters and time is the factor that has less significance. The parameters experiencing high variability are $K_{232}$, $K_{268}$, peroxide, and tocopherols, followed by acidity grade, 


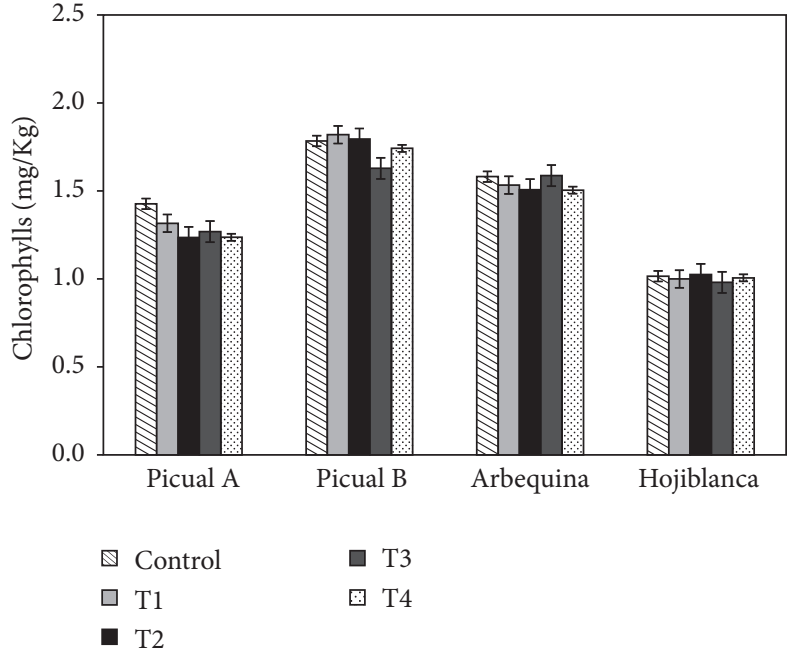

(a)

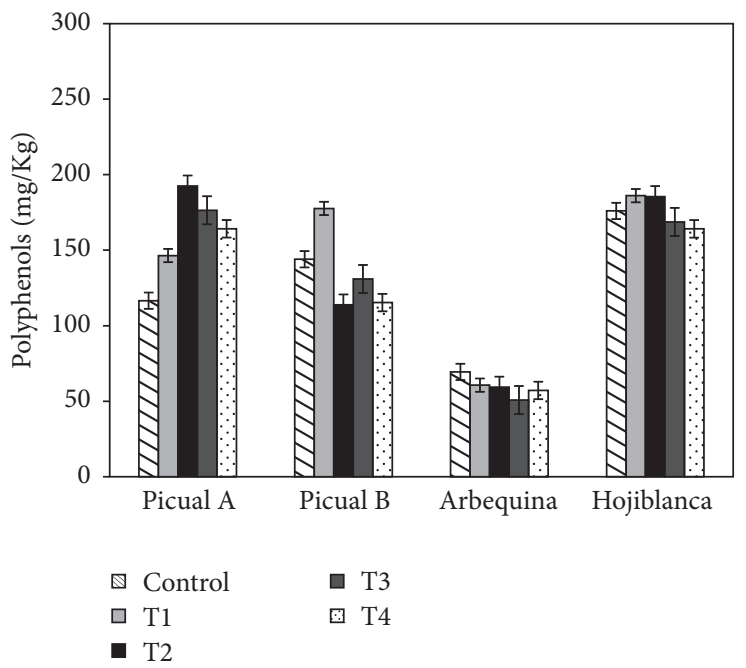

(c)

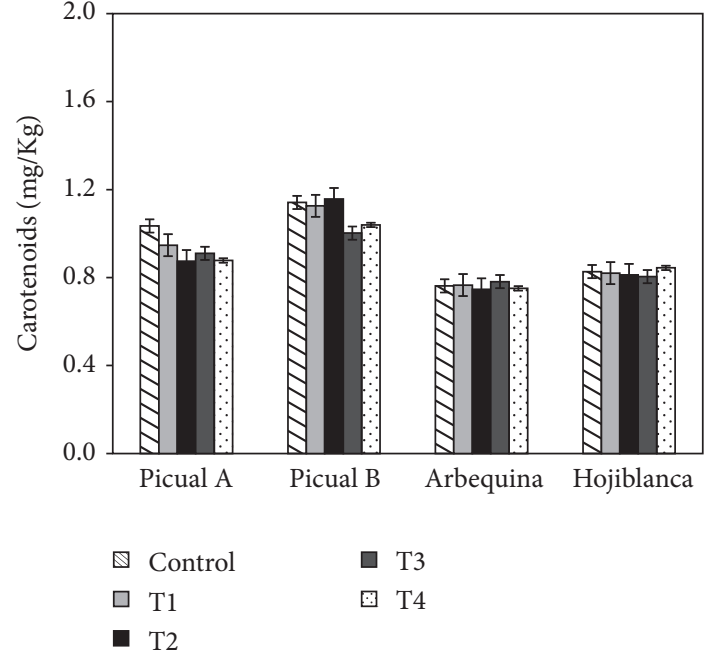

(b)

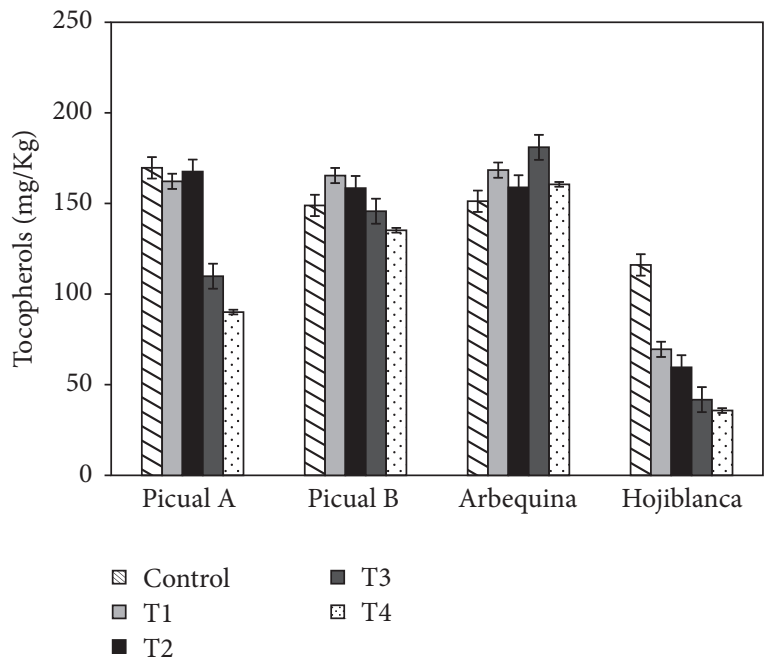

(d)

FIGURE 5: Influence of the heating treatments on the minority compounds: (a) chlorophylls, (b) carotenoids, (c) phenols, and (d) tocopherols.

TABLE 3: Analysis of variance (ANOVA).

\begin{tabular}{lcccccccc}
\hline Parameters & AG & PV & $K_{232}$ & $K_{268}$ & Polyphenols & Chlorophylls & Carotenoids & Tocopherols \\
& $P$ & $P$ & $P$ & $P$ & $P$ & $P$ & $P$ \\
\hline \multicolumn{1}{c}{ Main effects } & & & & & & & \\
Variety & 0.0000 & 0.0000 & 0.0000 & 0.0000 & 0.0000 & 0.0000 & 0.0000 \\
Temperature & 0.0000 & 0.0000 & 0.0000 & 0.0000 & 0.0422 & 0.0696 & 0.0252 & 0.0000 \\
Time & 0.2936 & 0.0135 & 0.0000 & 0.0000 & 0.3150 & 0.5975 & 0.0030 \\
\multicolumn{1}{c}{ Interactions } & & & & & & 0.00000 \\
Variety-temperature & 0.0011 & 0.0001 & 0.0027 & 0.0000 & 0.4174 & 0.0542 & 0.0025 \\
Variety-time & 0.0000 & 0.1596 & 0.0001 & 0.0000 & 0.0078 & 0.1279 & 0.0909 \\
Temperature-time & 0.0956 & 0.0071 & 0.0000 & 0.0000 & 0.8857 & 0.3909 & 0.0000 \\
\hline
\end{tabular}

The $P$ values show the statistical significance of each factor. Interaction level 2: nivel de integración " 2 ."

For $P<0.005$ the effects have a statistical significance over each parameter with a statistical confidence of $95.0 \%$. 
polyphenols, and carotenoids. The olive variety is the factor with the major influence on the variability.

\section{Conclusions}

This research simulates extreme storage, transport, or conservation conditions with high temperatures similar to the temperatures reached in countries with hot climate. The effects of these conditions on the quality of three olive oils varieties are conclusive about the quality of the olive oils of the three varieties studied and they can be extrapolated to other varieties for similar conditions.

The picual variety, in terms of quality parameters, shows changed values of AG, $\mathrm{PV}, K_{232}$, and $K_{268}$ compared to the limits established by the European Regulations for EVOO. The arbequina variety has similar behavior but only for the $\mathrm{PV}$ and the hojiblanca variety maintains its parameters within the EVOO category. However the sensory analysis of all the varieties samples determines that the oils became "virgin" and even "lampante" category after the heating treatments. The fatty acid profile is practically unchanged for the three varieties.

In relation to the minority compounds, the pigments are unaltered with the exception of picual A. The polyphenols content is also unaffected by the heating treatments. However the tocopherols content changes considerably with the exception of the picual B.

In view of the results the sensory analysis and the minority compounds are the most influenced after the treatments and due to their great influence in the preservation of the EVOO category the interest of this study to control all the traceability steps of the olive oil for commercialization is remarkable. The variance analysis (ANOVA) indicates that all the factors studied (olive variety, time, and temperature) have a great influence but the olive variety is the most relevant. It should be mentioned that the quality parameters more affected $\left(K_{232}, K_{268}\right.$, and peroxide) show the oxidation state of the olive oil.

\section{Competing Interests}

The authors declare that there is no conflict of interests regarding the publication of this paper.

\section{References}

[1] European Regulation (EC) No 852/2004 of the European Parliament and of the Council of 29 April 2004 on the hygiene of foodstuffs, Official Journal of the European Union L 139/1, 2004.

[2] Law 12/2013, of 2 August, on measures to improve the functioning of the food chain. Spanish Official State Gazette, no. 185, 2013.

[3] D. Boskou, "Olive oil composition," in Olive Oil Chemistry and Technology, AOCS Press, Champaign, Ill, USA, 1996.

[4] J. L. Harwood and P. Yaqoob, "Nutritional and health aspects of olive oil," European Journal of Lipid Science and Technology, vol. 104, no. 9-10, pp. 685-697, 2002.
[5] M. Servili, R. Selvaggini, S. Esposto, A. Taticchi, G. Montedoro, and G. Morozzi, "Health and sensory properties of virgin olive oil hydrophilic phenols: agronomic and technological aspects of production that affect their occurrence in the oil," Journal of Chromatography A, vol. 1054, no. 1-2, pp. 113-127, 2004.

[6] M. N. Vissers, P. L. Zock, A. J. Roodenburg, R. Leenen, and M. B. Katan, "Apparent absorption of olive oil phenols in humans," Journal of Nutrition, vol. 132, pp. 409-417, 2002.

[7] L. di Giovacchino, M. R. Mucciarella, N. Costantini, M. L. Ferrante, and G. Surricchio, "Use of nitrogen to improve stability of virgin olive oil during storage," Journal of the American Oil Chemists' Society, vol. 79, no. 4, pp. 339-344, 2002.

[8] L. Cinquanta, M. Esti, and M. Di Matteo, "Oxidative stability of virgin olive oils," Journal of the American Oil Chemists' Society, vol. 78, no. 12, pp. 1197-1202, 2001.

[9] F. Gutiérrez and J. L. Fernández, "Determinant parameters and components in the storage of virgin olive oil. Prediction of storage time beyond which the oil is no longer of 'extra' quality," Journal of Agricultural and Food Chemistry, vol. 50, no. 3, pp. 571-577, 2002.

[10] A. De Leonardis and V. Macciola, "Evaluation of the shelf life of virgin olive oils," Rivista Italiana Delle Sostanze Grasse, vol. 75, pp. 391-397, 1998.

[11] O. Okogeri and M. Tasioula-Margari, "Changes occurring in phenolic compounds and $\alpha$-tocopherol of virgin olive oil during storage," Journal of Agricultural and Food Chemistry, vol. 50, no. 5, pp. 1077-1080, 2002.

[12] E. Stefanoudaki, M. Williams, and J. Harwood, "Changes in virgin olive oil characteristics during different storage conditions," European Journal of Lipid Science and Technology, vol. 112, no. 8, pp. 906-914, 2010.

[13] E. Pagliarini, B. Zanoni, and G. Giovanelli, "Predictive study on tuscan extra virgin olive oil stability under several commercial conditions," Journal of Agricultural and Food Chemistry, vol. 48, no. 4, pp. 1345-1351, 2000.

[14] G. Di Lecce, A. Bendini, L. Cerretani, M. Bonoli-Carbognin, and G. Lercker, "Evaluation of 'home consumption conditions' on shelf-life of extra virgin olive oils," Industrie Alimentari, vol. 45 , no. 461, pp. 873-880, 2006.

[15] J. Velasco and C. Dobarganes, "Oxidative stability of virgin olive oil," European Journal of Lipid Science and Technology, vol. 104, no. 9-10, pp. 661-676, 2002.

[16] S. Gómez-Alonso, V. Mancebo-Campos, M. D. Salvador, and G. Fregapane, "Evolution of major and minor components and oxidation indices of virgin olive oil during 21 months storage at room temperature," Food Chemistry, vol. 100, no. 1, pp. 36-42, 2007.

[17] J. L. Guil-Guerrero and J. Urda-Romacho, "Quality of extra virgin olive oil affected by several packaging variables," Grasas y Aceites, vol. 60, no. 2, pp. 125-133, 2009.

[18] J.-R. Morelló, M.-J. Motilva, M.-J. Tovar, and M.-P. Romero, "Changes in commercial virgin olive oil (cv Arbequina) during storage, with special emphasis on the phenolic fraction," Food Chemistry, vol. 85, no. 3, pp. 357-364, 2004.

[19] C. Fadda, A. Del Caro, A. M. Sanguinetti et al., "Changes during storage of quality parameters and in vitro antioxidant activity of extra virgin monovarietal oils obtained with two extraction technologies," Food Chemistry, vol. 134, no. 3, pp. 1542-1548, 2012.

[20] D. Krichene, A. Allalout, V. Mancebo-Campos, M. D. Salvador, M. Zarrouk, and G. Fregapane, "Stability of virgin olive oil and 
behaviour of its natural antioxidants under medium temperature accelerated storage conditions," Food Chemistry, vol. 121, no. 1, pp. 171-177, 2010.

[21] D. Poljuha, B. Sladonja, K. B. Bubola et al., "Multidisciplinary approach to the characterization of autochthonous istrian olive (Olea europaea L.) varieties," Food Technology and Biotechnology, vol. 46, pp. 347-354, 2008.

[22] K. B. Bubola, O. Koprivnjak, B. Sladonja, and I. Lukić, "Volatile compounds and sensory profiles of monovarietal virgin olive oil from Buža, Črna and Rosinjola cultivars in Istria (Croatia)," Food Technology and Biotechnology, vol. 50, no. 2, pp. 192-198, 2012.

[23] K. Brkić Bubola, O. Koprivnjak, B. Sladonja, and I. Belobrajić, "Influence of storage temperature on quality parameters, phenols and volatile compounds of Croatian virgin olive oils," Grasas y Aceites, vol. 65, no. 3, article e034, 2014.

[24] N. Mulinacci, F. Ieri, G. Ignesti et al., "The freezing process helps to preserve the quality of extra virgin olive oil over time: a case study up to 18 months," Food Research International, vol. 54, no. 2, pp. 2008-2015, 2013.

[25] T. Cecchi, C. De Marco, P. Passamonti, and F. Pucciarelli, "Analytical definition of the quality of extra-virgin olive oil stored in polyethylene terephthalate bottles," Journal of Food Lipids, vol. 13, no. 3, pp. 251-258, 2006.

[26] A. I. Méndez and E. Falqué, "Effect of storage time and container type on the quality of extra-virgin olive oil," Food Control, vol. 18, no. 5, pp. 521-529, 2007.

[27] G. Pristouri, A. Badeka, and M. G. Kontominas, "Effect of packaging material headspace, oxygen and light transmission, temperature and storage time on quality characteristics of extra virgin olive oil," Food Control, vol. 21, no. 4, pp. 412-418, 2010.

[28] C. Samaniego-Sánchez, M. J. Oliveras-López, J. J. QuesadaGranados, M. Villalón-Mir, and H. L.-G. Serrana, "Alterations in picual extra virgin olive oils under different storage conditions," European Journal of Lipid Science and Technology, vol. 114, no. 2, pp. 194-204, 2012.

[29] M. Savarese, N. Caporaso, E. De Marco, and R. Sacchi, "Extra virgin olive oil overall quality assessment during prolonged storage in PET containers," in Proceedings in the CV- The 1st Global virtual Conference, vol. I, no. 1, pp. 761-770, 2013.

[30] R. Korifi, J. Plard, Y. Le Dréau, C. Rébufa, D. Rutledge, and N. Dupuy, "Highlighting metabolic indicators of olive oil during storage by the AComDim method," Food Chemistry, vol. 203, pp. 104-116, 2016.

[31] L. Cossignani, M. S. Simonetti, A. Neri, and P. Damiani, "Changes in olive oil composition due to microwave heating," The Journal of the American Oil Chemists' Society, vol. 75, no. 8, pp. 931-937, 1998.

[32] R. Malheiro, I. Oliveira, M. Vilas-Boas, S. Falcão, A. Bento, and J. A. Pereira, "Effect of microwave heating with different exposure times on physical and chemical parameters of olive oil," Food and Chemical Toxicology, vol. 47, no. 1, pp. 92-97, 2009.

[33] T. Mostafa, M. Seid, A. Elham, N. Shahram, and A. Omran, "Optimization of microwave-assisted extraction of cottonseed oil and evaluation of its oxidative stability and physicochemical properties," Food Chemistry, vol. 160, pp. 90-97, 2014.

[34] T. Albi, A. Lanzón, A. Guinda, M. C. Pérez-Camino, and M. León, "Microwave and conventional heating effects on some physical and chemical parameters of edible fats," Journal of Agricultural and Food Chemistry, vol. 45, no. 8, pp. 3000-3003, 1997.
[35] F. Caponio, A. Pasqualone, and T. Gomes, "Changes in the fatty acid composition of vegetable oils in model doughs submitted to conventional or microwave heating," International Journal of Food Science and Technology, vol. 38, no. 4, pp. 481-486, 2003.

[36] L. Cerretani, A. Bendini, M. T. Rodríguez-Estrada, E. Vittadini, and E. Chiavaro, "Microwave heating of different commercial categories of olive oil: Part I. Effect on chemical oxidative stability indices and phenolic compounds," Food Chemistry, vol. 115, no. 4, pp. 1381-1388, 2009.

[37] S. Adrover-Obrador, F. Comas, M. E. Dalmau et al., "Influencia de los tratamientos térmicos sobre las propiedades fisicoquímicas del aceite de oliva virgen extra," VII Congreso Español de Ingeniería de Alimentos, Ciudad Real. 84, 2012.

[38] Trade Standard Applying to Olive Oils and Olive-Pomace Oils. COI/T.15/NC no. 3/Rev. 7 May of 2013.

[39] Regulation (EEC) 2015/1830 of the Comission of 8 of july of 2015 which modifies the Regulation (EEC) no. 2568/91 on the characteristics of olive oil and olive-residue oil and on the relevant methods of analysis.

[40] S. C. Cunha, J. S. Amaral, J. O. Fernandes, and M. B. P. P. Oliveira, "Quantification of tocopherols and tocotrienols in Portuguese olive oils using HPLC with three different detection systems," Journal of Agricultural and Food Chemistry, vol. 54, no. 9, pp. 3351-3356, 2006.

[41] M. E. Mínguez, Clorofilas y Carotenoides, en Tecnología de Alimentos, Ediciones Universidad de Sevilla, Seville, Spain, 1997.

[42] A. Vázquez-Roncero, C. Janer del Valle, and M. L. Janer del Valle, "Determinación de polifenoles totales del aceite de oliva," Grasas y Aceites, vol. 22, pp. 350-355, 1973.

[43] S. Casal, R. Malheiro, A. Sendas, B. P. P. Oliveira, and J. A. Pereira, "Olive oil stability under deep-frying conditions," Food and Chemical Toxicology, vol. 48, no. 10, pp. 2972-2979, 2010.

[44] A. Carrasco-Pancorbo, L. Cerretani, A. Bendini, A. SeguraCarretero, G. Lercker, and A. Fernández-Gutiérrez, "Evaluation of the influence of thermal oxidation on the phenolic composition and on the antioxidant activity of extra-virgin olive oils," Journal of Agricultural and Food Chemistry, vol. 55, no. 12, pp. 4771-4780, 2007.

[45] A. Yahyaoui, G. Rigane, and R. B. Salem, "Microwave heating of different commercial Tunisian olive oil: regarding to exposure times on physical and chemical parameters properties," Biochemistry \& Physiology, vol. 3, article 131, 2014.

[46] M. Brenes, A. García, A. Guinda, M. C. Dobarganes, J. Velasco, and C. Romero, "Influence of thermal treatments simulating cooking processes on the polyphenol content in virgin olive oil," Journal of Agricultural and Food Chemistry, vol. 50, no. 21, pp. 5962-5967, 2002. 

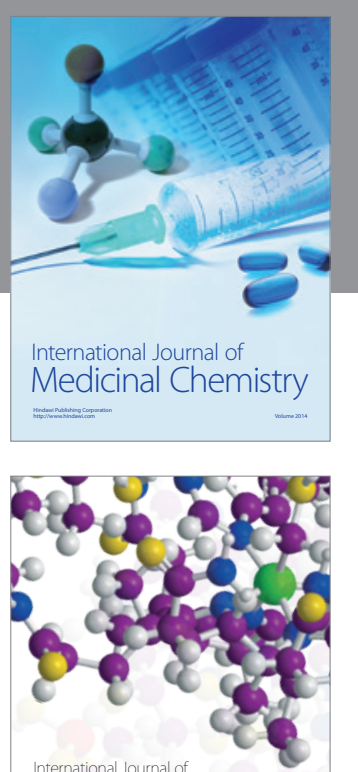

Carbohydrate Chemistry

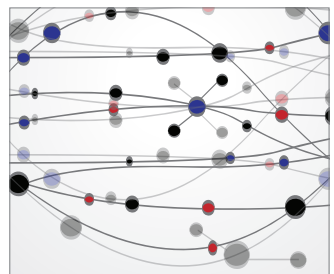

The Scientific World Journal
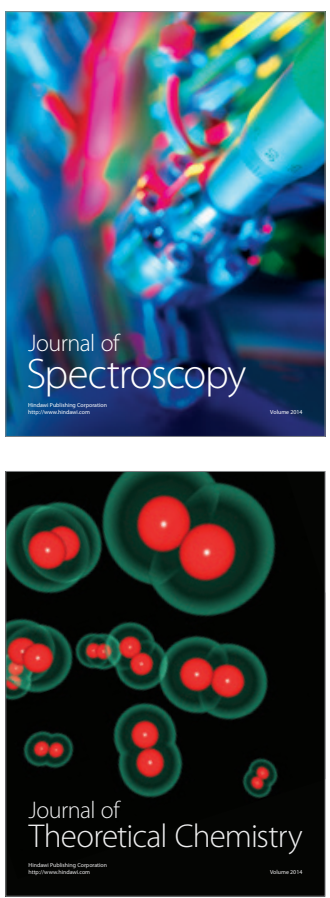
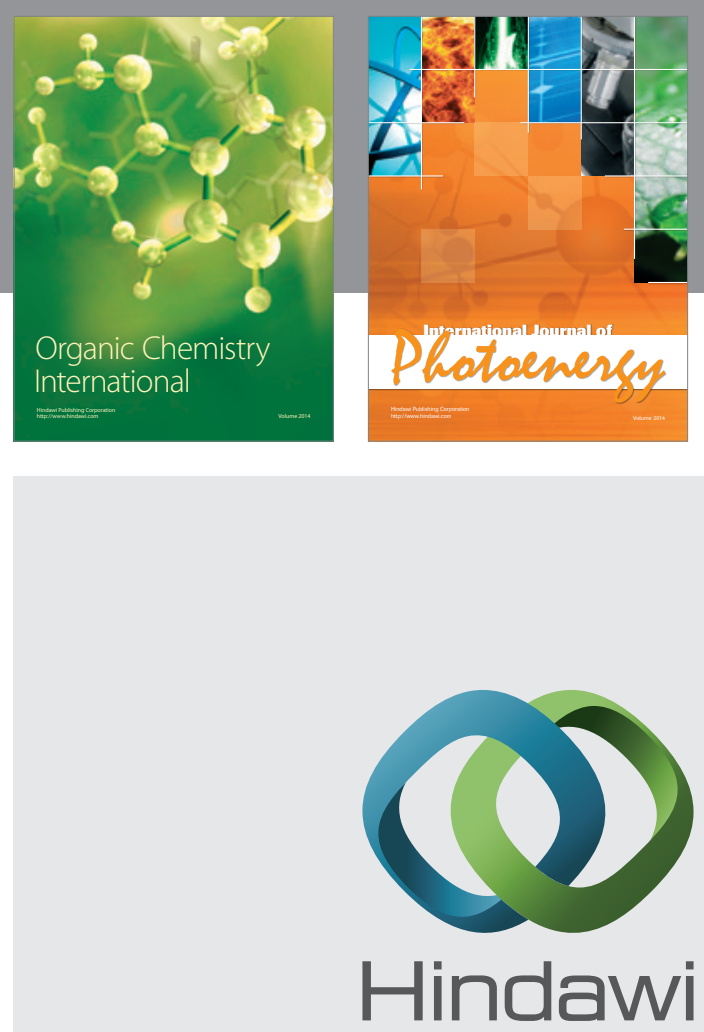

Submit your manuscripts at

http://www.hindawi.com

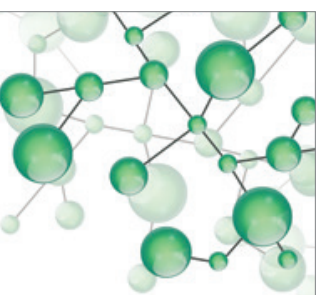

International Journal of

Inorganic Chemistry

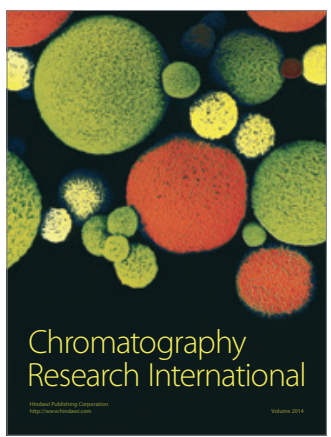

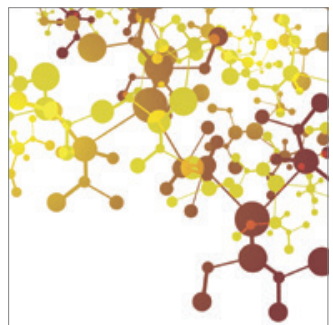

Applied Chemistry
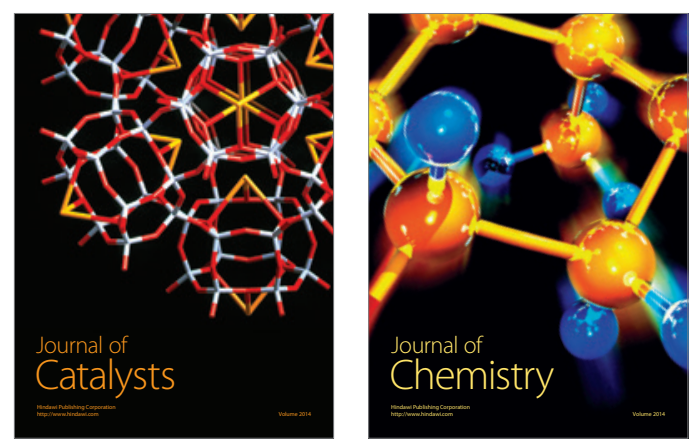
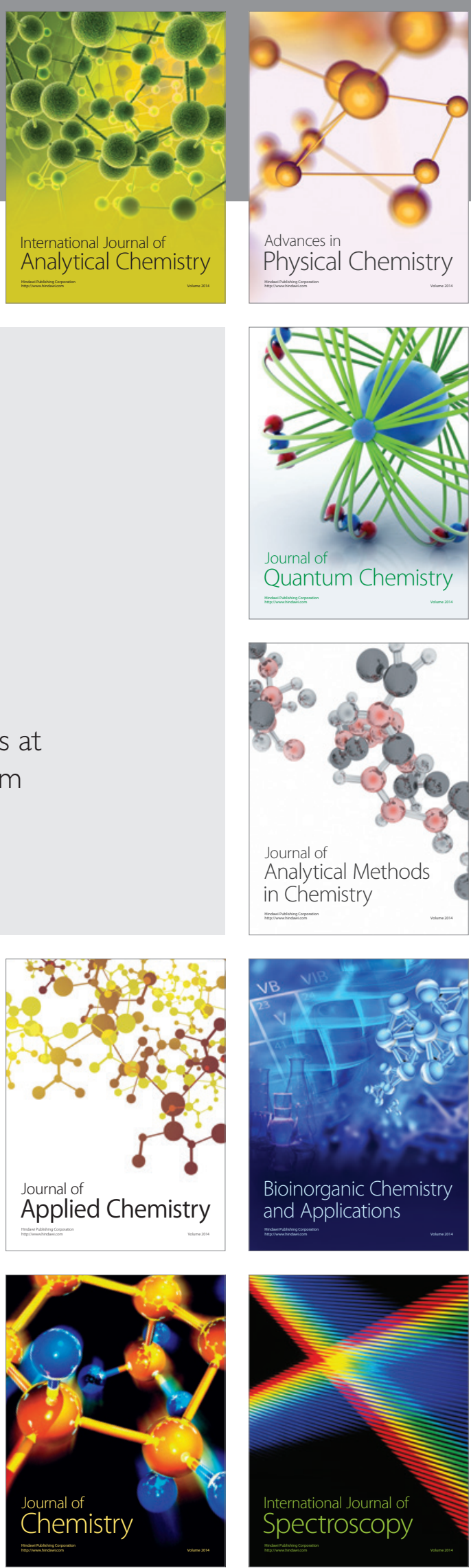